\title{
Educação e competências para o SUS: é possível pensar alternativas à(s) lógica(s) do capitalismo tardio?
}

\author{
Education and competences for the Brazilian Unified Health \\ System (SUS): is it possible to find alternatives \\ to the logic of late capitalism?
}

Abstract The transformations that have revolutionized the labor market in contemporary society make it necessary to think of new alternatives for training health care professionals, thereby establishing a new approach to the health problems of individuals and collectives. Based on these considerations, this paper sets out to discuss training in health - based on the concept of competencewith a focus on education for the Brazilian Unified Health System (SUS), using attempts to analyze and propose an alternative to the system entrenched in the logic of late capitalism as a theoretical benchmark. It is thus a reflection on the subject, correlating theory and praxis, in constant and relentless movement of construction, deconstruction and (re)construction of propositions. Key words Competences, Education, Capitalism
Resumo As transformações vividas no mundo do trabalho na sociedade contemporânea levam à necessidade de se repensar alternativas para a formação dos profissionais de saúde, permitindo, assim, a abordagem dos problemas de saúde dos sujeitos e das coletividades. Com base nessas considerações, o presente trabalho pretende discutir a formação em saúde - em torno do conceito de competência -, tendo como foco a educação para o SUS, tomando como marco teórico a tentativa de analisar e propor uma alternativa àquelas entrincheiradas na lógica do capitalismo tardio. Trata-se, pois, de uma reflexão sobre o assunto, correlacionando a teoria e a práxis, num movimento constante e incessante de construção, desconstrução e (re)construção de proposições.

Palavras-chave Competências, Educação, Capitalismo 


\section{Introdução}

As transformações vividas no âmago das sociedades contemporâneas, nas últimas décadas, têm reconfigurado as interações, demandando a necessidade de se (re)pensar as relações entre os indivíduos. De fato, questões emergentes de diversas ordens - tais como (1) a celeridade das transformações sociais, em um contexto no qual a produção de conhecimento é extremamente rápida, tornando ainda mais temporários os modelos elaborados no bojo da ciência ${ }^{1}$; (2) a frequente interrogação com relação aos valores até então considerados inquestionáveis²; (3) a sensível influência dos meios de comunicação na modulação do homem/profissional, consubstanciada em um genuíno "bombardeio" de imagens, a qual suscita menores possibilidades de reflexão sobre a vida, a inserção no mundo e a própria práxis $^{3}$; (4) a ascensão do neoliberalismo e da globalização, com o fortalecimento da organização da economia e das fluidas relações sociais em torno do mercado; e (5) a configuração de uma nova modalidade de organização do espaço-tempo social delineando as sociedades de controle, as quais operam nos deslizes de um sistema aberto, em contraposição às sociedades disciplinares, constituídas em torno de estratégias de confinamento ${ }^{4,5}$ - têm alterado marcadamente a vida dos sujeitos, transformando radicalmente a forma como se relacionam com o mundo.

Essas significativas mutações têm evidente impacto nos modos de operar a educação de homens e mulheres para a vida em sociedade, abrindo-se espaço para a reorientação dos processos ensino-aprendizagem, sobretudo na formação do profissional da saúde ${ }^{6}$. Nesse contexto, tem sido proposta a elaboração do currículo por competências, o qual diz respeito à necessidade de se reorientar a educação para o trabalho. Tal formulação tem sido defendida - por diferentes atores, nos fóruns de discussão da formação de profissionais da saúde - com especial enfoque nas relações da academia com o mundo do trabalho. Os desdobramentos desses debates no Brasil têm produzido esforços para o câmbio nos processos de formação profissional ${ }^{7,8}$, consubstanciados politicamente no surgimento de diferentes iniciativas, cabendo destaque à articulação levada a cabo pelos Ministérios da Saúde e da Educação, manifesta na elaboração de ações como o Programa de Incentivo às Mudanças Curriculares nas Escolas Médicas (PROMED) e o Programa Nacional de Reorientação da Formação Profissional em Saúde (PROSAÚDE) ${ }^{9,10}$.
São importantes tais avanços, mormente ao se considerar a necessidade de tornar o aparelho formador capaz de prover um egresso mais apto para lidar com os problemas da sociedade brasileira. No entanto, como se pretende que a formação profissional não seja formulada de modo a ser funcional à dinâmica de acumulação capitalista? Esta indagação torna-se mais clara ao se considerar que a opção conceitual pelas competências, como qualquer outra, está inscrita na história, na cultura e no desenvolvimento técnico-científico e ético-político ${ }^{11}$, não cabendo, portanto, a ingenuidade de não se perceber a ideologia, que é sempre vinculada à educação ${ }^{12}$ e à concepção e implantação de um currículo ${ }^{13}$. Ademais, tanto os processos de formação como os de certificação profissional e os de acreditação institucional, trazem a questão da competência em um campo de conflitos de interesse, nas quais emergem até então inusitadas relações de poder nas instituições ${ }^{5,14}$.

Com base nessas preliminares considerações, o presente artigo tem por escopo discutir as [possíveis] relações entre a orientação curricular por competências e a(s) lógica(s) de trabalho inerente(s) ao capitalismo tardio. Espera-se que tal reflexão contribua para a apresentação de tais conceitos, de modo a tornar os currículos menos funcionais ao neoliberalismo e às mazelas da economia de mercado.

\section{Educação para o SUS}

Os ideais do Sistema Único de Saúde (SUS) especialmente seu compromisso com a universalidade, a equidade e a integralidade do cuidado - permitem que tal proposta possa ser reconhecida como uma das políticas sociais mais importantes entre as já pensadas e implementadas no Brasi $1^{15}$. Contudo, ainda que os princípios, as diretrizes e os instrumentos legais do SUS estejam postos como realidade no cenário de saúde do país, parece haver um longo caminho a ser percorrido para sua efetivação, tendo em vista seu reconhecimento, no imaginário social, como espaço primordial de busca por cuidado.

A consolidação do SUS é um esforço em prol de um projeto de sociedade que amplia os limites do exercício da cidadania, tornando viva a ideia de que a saúde é dever do Estado e direito de todos $^{15}$. Ademais, significa contrapor-se à concepção inscrita na lógica capitalista, de acordo com a qual o acesso aos serviços de saúde pressupõe a inserção no processo produtivo. Posto isto, a consolidação do SUS passa a ser uma ta- 
refa diuturna, cuja responsabilidade pertence aos diferentes âmbitos de organização social - das esferas governamentais à sociedade civil organizada -, passando pelos profissionais da saúde, atores fundamentais para construção de um sistema humanizado, qualificado e radicalmente comprometido com a defesa da democracia e da qualidade de vida ${ }^{16}$.

Todavia, o desafio de concretizar a universalidade do acesso, a equidade e a integralidade das ações esbarra, em parte, no perfil de formação dos profissionais da saúde. Dentre os entraves postos, destacam-se a excessiva especialização observada em alguns cursos da área da saúde e o distanciamento entre tal formação e as necessidades da população brasileira. Nesse sentido, o Ministério da Saúde tem reforçado como uma de suas funções prioritárias o ordenamento da formação de recursos humanos para o setor saúde. Tal proposta, no entanto, esbarra em ciclo vicioso de difícil ruptura: hoje a disponibilidade de profissionais com o perfil desejado - generalista, com visão humanista e preparado para prestar cuidados contínuos e resolutivos à comunidade - é bastante pequena, fato que dificulta sobremaneira a formação de profissionais com tais características $^{10}$.

Em atenção a estes aspectos, muitas instituições de ensino superior brasileiras começaram a investir na mudança da formação profissional, buscando, neste movimento, contribuir com a transformação da atenção à saúde. A esse respeito, Lima e Feuerwerker ${ }^{17}$ caracterizam como eixos da política para a mudança na graduação das profissões da saúde (1) a implementação das Diretrizes Curriculares Nacionais dos cursos da área de saúde (DCN) - pelo lado da educação e (2) a adoção da integralidade como eixo orientador da formação objetivando a mudança dos processos de trabalho, pelo lado da saúde. O que se espera é formar profissionais habilitados para responder às necessidades da população brasileira e à operacionalização e à qualificação do SUS, buscando-se um egresso comprometido com seus princípios. A formação deve permitir o entendimento da necessidade de garantia do cuidado em todas as suas dimensões, das atividades de promoção e prevenção até aquelas que envolvem serviços com maior densidade tecnológica ${ }^{18}$. Ou seja, uma formação que garanta, simultaneamente, a excelência técnica e a relevância (bio)ética e social.

As DCN - considerando-se aqui Medicina ${ }^{19}$, Enfermagem ${ }^{20}$ e Odontologia ${ }^{21}$ - vêm ao encontro da consolidação dos princípios do SUS, quan- do propõem a construção de um perfil acadêmico e profissional de competências e habilidades para atuação, com qualidade e resolutividade, tendo como referencial os pressupostos da Reforma Sanitária e o reconhecimento do papel central do estudante no processo ensino-aprendizagem, na medida em que este deve ser um sujeito ativo de sua própria construção ${ }^{22,23}$. Especial destaque é dado ao princípio da formação generalista, necessária para que o graduado possa vir a superar os desafios do exercício profissional e da produção do conhecimento, condizentes com as necessidades de saúde da população brasileira ${ }^{24}$.

A formação de profissionais de saúde precisa considerar, ainda, o fortalecimento do modelo de atenção à saúde "usuário-centrado", no qual o compromisso essencial diz respeito às necessidades do usuário, como contrapartida do modelo "procedimento-centrado" atualmente hegemônico, no qual o ordenamento do ato de assistir à saúde é redutível, em grande medida, à produção - quase fordista... - de procedimentos. Desde esta perspectiva, o deslocamento da centralidade dos equipamentos tecnológicos para o terreno das tecnologias não equipamento é fundamental. O território das tecnologias leves - as que permitem operar os processos relacionais do encontro entre o trabalhador de saúde e do usuário - e das tecnologias leve-duras - os saberes estruturados que permitem o processo de trabalho em saúde - precisam ser intensamente expandidos ${ }^{25}$, além da valorização equivalente e articulada dos determinantes biológicos, sociais e ambientais da saúde e da doença ${ }^{26}$.

Muitos são os desafios na educação para o SUS, mas múltiplas são igualmente as possibilidades, cabendo destaque principal às atividades de integração ensino-trabalho-cidadania. Profissionais de saúde, docentes e estudantes devem estar inseridos no mundo do trabalho, na perspectiva da educação permanente, tendo em vista qualificar a formação e fortalecer o SUS. A concepção de educação permanente vai para além de um processo de educação continuada baseado em "adaptação e conformação" 27 , apostando no viés da transformação (como na educação popular em saúde). É, ao mesmo tempo, prática de ensino-aprendizagem - produção de conhecimento no cotidiano dos serviços - e política de educação na saúde - ensino que contribui à construção do SUS. Isso porque aposta-se que a educação permanente seja capaz de possibilitar, ao mesmo tempo, o desenvolvimento pessoal daqueles que trabalham na área da saúde e a consolidação das instituições, reforçando a relação das ações de 
formação com a gestão do sistema e dos serviços, com o trabalho da atenção à saúde e com o controle social. A possibilidade de transformar as práticas profissionais existe, na medida em que as perguntas e as respostas são construídas a partir da reflexão de trabalhadores e de estudantes sobre o trabalho que realizam ou para o qual se preparam. A educação permanente deve se inscrever no mundo como aprendizagem-trabalho, ou seja, capaz de acontecer no cotidiano das pessoas e das organizações, sendo consubstanciada a partir dos problemas enfrentados na realidade e levando em consideração os conhecimentos e as experiências que os sujeitos já albergam.

Ampliar - e rediscutir - o papel das instituições de ensino superior é fundamental nesse processo. Transformar a formação e a atenção à saúde são movimentos simultâneos e complementares. A mudança das instituições formadoras só faz sentido se for para a qualificação do SUS, reconhecendo-se que existem movimentos localizados, os quais precisam ser ampliados e integrados, para que alcancem resultados efetivos no conjunto do cuidado à saúde. Neste contexto, os currículos por competências têm sido divisados como boas alternativas para a implantação das transformações consideradas seminais para a nova lógica de formação dos profissionais de saúde.

$\mathrm{O}(\mathrm{s})$ currículo(s) organizado(s) por competências e a formação na área da saúde: polissemia e opções teórico-práticas

O conceito de competência tem origem no discurso empresarial tendo sido, ulteriormente, incorporado por sociólogos e economistas ${ }^{28}$ e amplamente discutido no âmbito da pedagogia contemporânea, incluindo os debates no campo da formação laboral em saúde. Todavia, um dos entraves à apreciação desta questão é a polissemia do termo - especialmente no domínio de sua utilização como proposta orientadora dos currículos -, sendo essencial conhecer as diversas abordagens de competência e seus desdobramentos, tendo em vista uma opção crítica, intencional e transformadora. É precisamente nesse sentido que Frigotto ${ }^{29}$ chama à atenção para o caráter das disputas teóricas travadas no espaço acadêmico, cujo caráter ético-político diz respeito ao papel da teoria na compreensão e na transformação do modo social, mediante o qual os seres humanos produzem sua existência, ainda sob a égide de uma sociedade classista, estruturada na extração combinada de mais-valia ab- soluta, relativa e extra ${ }^{29}$. As escolhas teóricas, neste sentido, não são nem neutras, nem arbitrárias tenha-se ou não consciência disso.

Um dos principais articuladores da pedagogia centrada na competência é Perrenoud, o qual a caracteriza como a capacidade de agir eficazmente em um determinado tipo de situação, apoiada em conhecimentos, mas sem limitar-se a eles en $^{30}$ O que está em pauta não é a aquisição pura e simples de conhecimentos, mas o discernimento para mobilizá-los frente à determinada situação.

$\mathrm{Na}$ esfera da formação profissional, a competência relaciona-se aos esquemas heurísticos ou analógicos próprios do campo de atuação, em processos intuitivos, em procedimentos de identificação e resolução dos problemas ${ }^{30}$. Além disso, supõe, igualmente, o desenvolvimento de estratégias mentais, curiosidade, busca de significado, processos de identificação, que nascem tanto da formação como da experiência ${ }^{30}$. Com efeito, no mundo do trabalho, pôde-se observar a transição do conceito clássico de qualificação profissional para uma concepção de competência, em função de novas demandas do setor produtivo e da falência dos métodos destinados a adaptar pessoas aos mercados e aos postos de trabalho. A crise na qualificação decorre da inserção das economias em mercados globalizados, da crescente exigência de competitividade e de produtividade e da vertiginosa incorporação de novas tecnologias - duras - que requerem flexibilidade e polivalência dos trabalhadores ${ }^{31}$.

As capacidades psicomotoras - também descritas como habilidades - expressam o domínio da maneira de se fazer algo. São resultados das aprendizagens consolidadas na forma de habitus ou do "saber-fazer", igualmente mobilizados na construção das competências profissionais ${ }^{32}$. Tais sentidos se aproximam daquilo que Moreira ${ }^{33}$ ao retomar a noção de hábito (habit) na obra de John Dewey - descreveu como maneiras de observar, pensar, refletir, manejar certos utensílios, caracterizando o modo de fazer de cada profissional e convertendo a experiência em algo aproveitável em outras oportunidades. A competência pode ser entendida, pois, como uma "inteligência da prática", "astuciosa” " "criativa”, empregada com vistas a colocar algo em ação e fundamentando-se na mobilização de conhecimentos adquiridos, absolutamente capazes de sofrer reformulações diante dos eventos. O encontro cotidiano com o inusitado, portanto, pode ser considerado um aspecto qualificador para todos os trabalhadores envolvidos nas diferentes situações apresentadas na vida laboral ${ }^{34,35}$. 
Tal abordagem não trata apenas de afirmar que o trabalho é "princípio educativo" - uma técnica didática de "aprender fazendo" -, mas destacar que há uma inteligência que se mistura àquelas das instruções e dos equipamentos; é aquela dos homens e das mulheres confrontados com a resistência dos objetos e das situações sobre as quais intervêm ${ }^{29,36-39}$.

Desde esta perspectiva, Perrenoud ${ }^{30}$ defende que currículos voltados para a construção de competências devem promover uma limitação na quantidade de conhecimentos ensinados e exigidos, dando prioridade aos conteúdos que possam ser exercitados pela mobilização em situações complexas. Não se trata, evidentemente, de negar a importância dos saberes em prol de uma formação tecnicista, mas sim da valorização de conhecimentos mobilizáveis e relacionados à experiência. Nesse mesmo sentido, Silva e Egry ${ }^{40}$ defendem que o processo ensino-aprendizagem alicerçado em competência pressupõe saberes intensamente trabalhados, para que possam ser mobilizados de acordo com as situações complexas e imprevisíveis - ou seja, não se poderiam formar competências por meio de um currículo que privilegie apenas a transmissão do conteúdos, sem promover situações em que esse conhecimento seja empregado em contextos vividos. Essas ideias foram bem consolidadas por Desaulniers ${ }^{41}$ ao mencionar necessidades pedagógicas para desencadear a construção de competências:

Construir competências implica o planejamento de situações suficientemente desafiadoras, a ponto de produzirem um estado, um clima de instigação/investigação junto ao formando; que as ações pedagógicas sustentem-se em problemáticas que contenham/desvelem/impliquem, tenham outras problemáticas nelas imbricadas, capazes de despertar o contínuo interesse do formando pela descoberta, pelo novo, pelo inusitado. Ou seja, pela busca maior da compreensão sobre a complexidade que constitui o real e, assim, tenha condições de interagir com ele com mais eficácia: com competência, como trabalhador e cidadão $0^{41}$.

É nesse sentido que Perrenoud ${ }^{30}$ - ao suscitar a ideia de um ensino voltado para a construção de competências - questiona se não se estaria no momento de substituir a reflexão especulativa e idealista por uma transposição didática apoiada em uma análise prospectiva e realista das situações de vida. Assim, para Costa ${ }^{42}$, a primazia das competências sobre os conhecimentos assume relevância fundamental nas decisões curriculares. A questão que se coloca, neste âmbito, é a qual senhor essa análise prospectiva e realista das situações de vida poderá servir. Veja-se um pouco mais deste domínio na seção a seguir.

\section{A crítica: a formação por competências no século XXI - capitalismo tardio e sociedade de controle}

A crítica à pedagogia das competências pode ser articulada a partir de dois focos principais: A questão prevalentemente econômica - pertencimento aos ditames de produção no capitalismo tardio - e a questão de esteio ético-político - inscrição na lógica das sociedades de controle.

Algumas abordagens da pedagogia das competências - como o condutivismo e o funcionalismo - guardam relação com a eficiência e a adaptação para o mercado de trabalho. O desempenho efetivo é o elemento central e o interesse está nos resultados (produtos) e não nos processos desenvolvidos para atingi-los ${ }^{31,43}$. Neste contexto, é tecida a mais importante crítica a esta modalidade pedagógica, que se refere à sua inscrição na lógica do capitalismo tardio:

Justifica-se a exclusão e a desigualdade como elementos necessários à competitividade. Busca-se firmar uma consciência alienada de que os vencedores ou os incluídos devem-no a seu esforço e competência. Os excluídos, os derrotados ou os miseráveis do mundo pagam o preço de sua incompetência ou de suas escolhas. (...) No plano ideológico, desloca-se a responsabilidade social para o plano individual. Já não há políticas de emprego e renda dentro de um processo de desenvolvimento social, mas indivíduos que devem adquirir competências ou habilidades no campo cognitivo, técnico, de gestão e atitudes para se tornarem competitivos e empregáveis ${ }^{29}$.

Dessa maneira, a noção de competências aplicada à educação passa a orientar um ensino voltado às necessidades do mercado, ou seja, para os atributos que o mercado requisita para inserção do trabalhador. Nessa direção, o papel emancipatório de construção da cidadania - tão caro à educação e às concepções do SUS - é relevado a um segundo plano, o qual passa a ser funcional às necessidades do capital, no sentido de ampliar os mecanismos de exploração produtiva. Em relação a este ponto, cabe ressaltar que as novas conformações do capital - muito além de alterar as relações de produção - têm provocado profundo impacto no ordenamento social. Disseminam-se dispositivos de controle que passam a atravessar e a equacionar toda a organização da sociedade, forjando uma modalidade de organização social que serve à dinâmica de captura do 
capitalismo contemporâneo. Tal reorganização consubstancia uma lógica de sociedades de controle $e^{4,5}$, emergindo como resposta à crise das sociedades disciplinares:

Nesses últimos anos, a sociedade mudou e os indivíduos também; eles são cada vez mais diversos, diferentes e independentes. Há cada vez mais categorias de pessoas que não estão submetidas à disciplina, de tal forma que somos obrigados a pensar o desenvolvimento de uma sociedade sem disciplina ${ }^{44}$.

As sociedades disciplinares, que sucedem as ainda coexistindo com - sociedades de soberania ${ }^{4}$, são marcadas pela organização em termos de espaços de confinamento - lídimos moldes, nos quais se opera o poder em diferentes dimensões circunscritas - cujo projeto ideal pode ser reconhecido na fábrica: concentrar, distribuir no espaço, ordenar no tempo, compor no espaçotempo uma força produtiva cujo efeito deve ser superior à soma das forças elementares -, nos quais a disciplina é exercida de forma institucionalizada, havendo a necessidade de se deslocar de um âmbito circunscrito para o outro ao longo da vida:

O indivíduo não cessa de passar de um espaço fechado a outro, cada um com suas leis: primeiro a família, depois a escola ("você não está mais na sua família"), depois a caserna ("você não está mais na escola"), depois a fábrica, de vez em quando o hospital, eventualmente a prisão, que é o meio de confinamento por excelência ${ }^{4}$.

A crise dos confinamentos, anunciada por Kafka $^{45,46}$ e agudizada pós a Segunda Guerra Mundial, representa a agonia ante a precipitação em termos de novas formas de exercício do poder engendradas em termos de controle. A transição para esta modalidade de ordenação social é discutida por Foucault, o qual prevê o temível cenário $^{47,48}$ :

Hoje, o controle é menos severo e mais refinado, sem ser, contudo, menos aterrorizador. Durante todo o percurso de nossa vida, todos nós somos capturados em diversos sistemas autoritários; logo no início na escola, depois em nosso trabalho e até em nosso lazer. Cada indivíduo, considerado separadamente, é normatizado e transformado em um caso controlado por um IBM. Em nossa sociedade, estamos chegando a refinamentos de poder os quais aqueles que manipulavam o teatro do terror [nas execuções penais públicas] sequer haviam sonha$d o^{47,48}$.

O cerne da passagem de uma a outra sociedade - das Memórias da casa dos mortos de Fiodor Dostoiévski ${ }^{49}$ a O processo de Franz Kafka ${ }^{45}$ - pode ser compreendido na transformação da fábrica em empresa, em especial a partir da reorganização produtiva em que o coração de fábrica se desfaz e a produção passa a ser realizada de maneira descentralizada, confundindo o território da produção ao território da cidade e da própria esfera privada (a casa), quiçá afim à narrativa do Show de Truman. O trabalho é realizado em todos os lugares: no escritório, no domicílio, na rua, no aeroporto, dentre outros. Desde esta perspectiva, percebe-se que na fábrica - um corpo modelo da sociedade disciplinar marcado pelo adestramento - se estabelecia um equilíbrio da massa (de trabalhadores), cujo sentido era maximizar a produção e minimizar os salários, protagonizado pelos patrões - os quais vigiavam cada um dos elementos da massa - e pelo sindicato - o qual mobilizava uma massa de resistência -, em uma eterna tensão. Ao contrário, na empresa - uma alma, um gás, modelo da sociedade de controle tipificado pela captura da participação - há um grande esforço para se impor/compor uma modulação para cada salário, a partir de um sistema de recompensa por performance, em um estado de perene metaestabilidade, no qual se está imerso, continuamente, em uma rivalidade incontornável, marcada pela contraposição dos indivíduos entre $\mathrm{si}^{4}$. Não há mais uma massa de resistência organizada - p. ex., em um sindicato -, mas uma multiplicidade de trabalhadores precarizados que passam a criar novas formas de resistência: acaba-se com a submissão do trabalhador na prescrição do trabalho, mas instituem-se novos mecanismos de controle ${ }^{48}$.

A nova faceta é clara: o molde - família, escola, caserna, fábrica, hospital, prisão ${ }^{49}$ - é substituído pela modulação - a empresa, o mercado , uma moldagem autodeformante que se altera a cada instante. O princípio modulador se manifesta em controlatos (p. ex., o salário por mérito), os quais, de forma complexa, se imbricam em uma geometria variável, imagética e virtual, como formulada por Virilio ${ }^{50}$. Ademais, se os polos identificados por Foucault - o par indivíduo-massa ${ }^{44}$ - são a tônica das sociedades disciplinares, no controle o que importa é a cifra, uma senha, a qual marca o acesso à informação ou à rejeição $0^{47}$ - como no filme Gattaca ${ }^{51,52}$-, tornando os indivíduos dividuais e a massa mera amostra. O deslize se torna explícito, também, no caso do dinheiro: das moedas cunhadas em ouro (limitadas tempo-espacialmente), medida-padrão da disciplina, para câmbios flutuantes, transações de mercado ${ }^{4}$. Desvia-se da toupeira monetária para a serpente financeira, em uma passagem que não se faz por escoamento - ao contrá- 
rio, dá-se de modo turbilhonado - mas que é plenamente perceptível:

O controle não é uma disciplina. Com uma estrada não se enclausuram pessoas, mas, ao fazer estradas, multiplicam-se os meios de controle. Não digo que esse seja o único objetivo das estradas, mas as pessoas podem trafegar até o infinito e "livremente", sem a mínima clausura, e serem perfeitamente controladas. Esse é o nosso futuro ${ }^{4}$.

Tal é o futuro que, tornando-se passado, já se faz plenamente presente, especialmente no âmbito da educação:

No regime das escolas: as formas de controle contínuo, avaliação contínua, e a ação da formação permanente sobre a escola, o abandono correspondente de qualquer pesquisa na Universidade, a introdução da 'empresa' em todos os níveis de escolaridade ${ }^{4}$

Em última análise, a crítica insistente aos mecanismos disciplinares - na escola médica tem se associado ao exercício ondulante das forças de controle. Por exemplo, a importância da formação profissional em saúde nos dias atuais convive com o enfraquecimento das fronteiras das instituições de ensino ${ }^{52}$, as quais deixam de ser espaços de confinamento - os muros da universidade não definem mais o espaço no qual se estuda: estuda-se em todo lugar e em todo tempo disponível, em uma nítida ocupação das coordenadas espaço-temporais ${ }^{53}$; este é o caso da proposta, cada vez mais recorrente, de uma [necessária] integração ensino-serviço-comunidade. $\mathrm{O}$ hospital, antes o cenário de prática quase exclusivo no qual a relação ensino-aprendizado se dava de maneira bem disciplinada, progressivamente torna-se menos importante, adquirindo relevância os aparatos/controlatos de saúde descentralizados no território. Em verdade, o próprio território torna-se cenário de formação de uma relação de ensino-aprendizagem que possui uma dupla perspectiva de controle: ao se requerer menos disciplina e mais autonomia do estudante, são os mecanismos de controle que passam a delinear as práticas de ensino-aprendizagem, exercendo-se uma estrita vigilância sobre a população inscrita em tais cenários.

De outro lado, as propostas de educação permanente (também de educação à distância), especialmente aquelas envolvendo todos os atores - estudantes, docentes, profissionais de saúde, profissionais administrativos, doentes e familiares, caracterizando certo tipo de porosidade ao entorno - evidenciam a expansão das intervenções educacionais para além dos limites da universidade. Um dos objetivos amplos deste pro- cesso é formar o cidadão integral, a partir da participação/intervenção/controle de todos os envolvidos, os quais assumem o papel de educadores, atuando/interferindo nos diferentes aspectos das respectivas formações.

É neste contexto que ganha importância a avaliação formativa, ininterrupta, capaz de olhar o processo nos vários momentos-lugares, sem limites de ensino-aprendizagem - na universidade e fora dela -, um dos mais efetivos métodos para o controle. Observar, de perto, o progresso dos aprendizes, podendo interferir de forma mais ou menos recorrente está inscrito nesta lógica. As notas, formalização da disciplina, são substituídas pelo conceito fluido de suficiência - "você foi insuficiente na atividade de hoje..." -, uma medida da competência; se antes era possível receber uma nota para, então, se passar de uma série a outra, agora é dado um grau suficiente ou insuficiente, para se manter (indefinidamente) no processo de formação. A "formatura" passa a significar, outrossim, não o término do curso de fato, mas um novo patamar de um processo de educação que não cessa - nunca - de escoar, ou seja:

(...) nas sociedades de controle nunca se termina nada, a empresa, a formação, o serviço sendo os estados metaestáveis e coexistentes de uma mesma modulação, como que um deformador universal ${ }^{4}$.

As consequências disto não se fazem tardar: ampliam-se as fileiras constituídas por eternos estudantes, para os quais o conhecimento - agora, muita vezes, sinônimo de informação - torna-se rapidamente ultrapassado, tornando impositiva a aquisição, infrene, de novas informações, as quais são a resposta ao status quo de competitividade exigida pelas conformações do capitalismo tardio. A atualização deixa, assim, de ser pressuposto para uma boa prática, passando a ser, nas palavras de Chevitarese, quase uma obsessão cultural ${ }^{46}$.

Estes novos processos têm profundas implicações na (in)formação do profissional de saúde e, por consequência, na sua prática. De fato, a ideologia dominante na saúde - eficazmente incorporada ao discurso oficial - se concretiza em novos contornos. Os hospitais - célebres espaços de confinamento, como bem demonstrado em toda a atitude policialesca da psiquiatria no último século ${ }^{54}$ - deram lugar à medicina sem médico nem doente 4 . De um lado, a clínica do corpo sem órgãos ${ }^{55}$ - ou, quiçá, dos órgãos sem cor$p o^{56}$ - operando através de uma noção de risco que estratifica e orienta cada classe da população a um certo tipo de prescrição. De outro, a ascensão da saúde pública/coletiva - como nos deba- 
tes sobre promoção à saúde ${ }^{57}$ - torna todos os sujeitos doentes em potencial, para os quais o adiamento da enfermidade tem como preço a constante vigilância - à saúde! -, a régia observância às orientações dos profissionais. Este é, precisamente, o caso dos sintomáticos respiratórios (pessoas que tossem há mais de três semanas), potenciais tuberculosos, os quais deverão ser identificados nas comunidades, rastreados para a infecção pelo Mycobacterium tuberculosis (através da baciloscopia de escarro) e tratados, impedindo-se, assim, a disseminação do $\mathrm{mal}^{58}$. No mesmo movimento tem-se que

(...) na crise do hospital como meio de confinamento, a setorização, os hospitais-dia, o atendimento a domicílio puderam marcar de início novas liberdades, mas também passaram a integrar mecanismos de controle que rivalizam com os mais duros confinamentos ${ }^{4}$.

Ainda sobre a saúde, cabe o comentário acerca do desenvolvimento da biotecnociência. A colonização da vida nua - a zoe aristotélica $^{59}$, redimensionada por Agamben ${ }^{60}$ - a qual se concretiza cada vez mais na possibilidade da manipulação genética, têm explicitado os riscos aos quais se pode estar sujeito, em decorrência de uma má herança genética. Podem ser mencionados, neste âmbito, os testes para detecção do risco de câncer de mama - ou de outras neoplasias -, o qual, uma vez identificado, deverá motivar um controle permanente para o diagnóstico e tratamento da condição mórbida. Eis o mundo de Gattaca! Como no filme ${ }^{51}$, todos podem ser virtualmente "portadores" de condições mórbidas diversas, cabendo, assim, a necessidade de se desenvolver tecnologias capazes de identificar e extirpar os maus genes, quiçá no momento - ou antes mesmo - da concepção. Como nas palavras de Renato Manfredini Júnior, o Renato Russo, nos deram espelhos e vimos um mundo doente ${ }^{61}$.

Com base neste panorama, torna-se defensável a afirmação de que a pedagogia das competências, além de servir ao mercado, senhor do capitalismo tardio, está inscrita neste emergente ordenamento - o controle-, especialmente ao se perscrutar os elementos concernentes à educação permanente e à avaliação. Com efeito, na medida em que a pedagogia das competências pretende formar profissionais capazes de responder às necessidades de saúde da população ${ }^{8}$, e que tais necessidades estão cada vez mais inscritas na nova ordem mundial tipificada nas sociedades de controle, a conclusão não se faz tardar: os novos modelos pedagógicos e os inovadores currículos por competências podem ser caracte- rizados como um controlato $^{5,62}$, ao menos da maneira segundo vem sendo pensados e executados na atualidade.

O currículo por competência na formação de profissionais para o SUS: resistência ao capitalismo tardio

A partir das críticas ao conceito de competência aqui apresentadas, é possível propor uma alternativa teórica para reflexão, quiçá como resistência à lógica do capitalismo tardio / sociedade de controle: o conceito de competência dialógica, o qual pode ser visto como um contraponto à concepção neoliberal de competência. De acordo com Lima $^{63}$, a competência dialógica trabalha com o desenvolvimento combinado das capacidades cognitivas, psicomotoras e afetivas, as quais conformam distintas maneiras de realizar, com sucesso, tarefas essenciais e características de determinada prática profissional em diferentes contextos:

A abordagem dialógica de competência reconhece e considera a história das pessoas e das sociedades nos seus processos de reprodução ou de transformação dos saberes e valores que legitimam os atributos e os resultados esperados numa determinada área profissional. Esta explicitação permite um processo mais aberto de exploração das distintas concepções, interesses, valores e ideologias, que invariavelmente governam e determinam a intencionalidade dos processos educativos, porém nem sempre são discutidos de um modo mais participativo e democrático pela sociedade ${ }^{63}$.

A construção de competências dialógicas - as quais se apresentam como uma alternativa à formação na lógica do capitalismo tardio - se insere na matriz crítico-emancipatória, trazendo a ideia de competências profissionais ampliadas, contextualizadas, historicamente definidas e coletivamente construídas, conferindo grande importância à dimensão social do conhecimento - relação entre os indivíduos e dos mesmos com o mundo - os quais são fundamentais para o desenvolvimento da aprendizagem. Além disso, enfatiza a construção das competências para a autonomia e para a emancipação de relações de trabalho alienadas - e capturadas - em busca da formação integral e ampliada - ou seja, a articulação entre as dimensões profissional e sociopolítica ${ }^{64}$. Nesse sentido, tal concepção de competência se afasta da perspectiva individualizante e culpabilizadora, na medida em que os processos de ensino-aprendizagem e de construção do conhecimento, no campo saúde, se dão no âmbito de linhas de força coletivas. A competência não é 
mais um requisito individual que serviria para integrar os profissionais ao mercado de maneira subordinada - à lógica das modulações operadas no bojo dos ditames do controle -, mas um conjunto de saberes e práticas coletivamente desenvolvidos ao longo do processo de formação.

As propostas de formação e de exercício do trabalho interdisciplinar já estão colocadas como realidade na sociedade brasileira, ao menos para a área da saúde. Prova disso - conforme descreve Ceccim e Feuerwerker ${ }^{7}$ - é a constância da designação do trabalho em equipe em qualquer circunstância propositiva de elevação da qualidade do trabalho e da formação em saúde. A orientação do trabalho em equipe consta tanto das diretrizes para a formação dos profissionais da saúde, quanto dos pressupostos para o exercício profissional no SUS.

A relação dos profissionais nas equipes de saúde é classificada por Gomes et al. ${ }^{65}$ como essencial para a eficácia do trabalho em saúde, à medida que existam pontos de confluência e que suas interfaces sejam valorizadas. $\mathrm{O}$ trabalho dos diferentes profissionais deve ser orquestrado de forma a apresentar coerência interna -, tendo a relação com o usuário como condutora das ações. A partir do contato com o usuário - fundamentado no acolhimento, vínculo e escuta -, o ritmo e o arranjo das práticas devem ser definidos. É nessa relação entre sujeitos - usuários e trabalhadores - que se determinam quais profissionais vão atuar e quais serão a amplitude, a sequência e a intensidade de suas participações. Henriques ${ }^{66}$ chama a atenção para a contradição entre a necessidade de transformação na formação e nas práticas de todas as profissões da saúde, criticando a perspectiva vigente de formação isolada de cada profissão:

Para além do modo como essas profissões produzem um cuidado, é preciso resultar para o usuário algo bom na perspectiva de seu desejo e expectativa e ser mais completo e solidário nas ações desenvolvidas por toda equipe. O ponto de vista apresentado é o de não haver necessidade de que uma ação profissional se sobreponha à outra, mas que, ao possuírem aspectos que são diversos no seu campo específico de saber e de cuidar, são todas igualmente importantes para o usuário, na capacidade de entendê-lo de modo abrangente, na sua singularidade (...). O espaço de interseção entre serviço e formação é rico em possibilidade para produção de novos saberes e práticas e também para a aquisição de condutas interprofissionais na produção do cuidado ${ }^{66}$.

A partir dessas considerações, torna-se perceptível a relevância de pensar a concepção de competência em termos coletivos, interdisciplinares, com inscrição nas - e como questionamento das - coordenadas sociais vigentes, não como modo de reprodução das mesmas ${ }^{67}$, mas sim de crítica atuante à lógica do capitalismo tardio e aos espúrios mecanismos de captura e de exercício de poder das sociedades de controle. Com efeito, deve-se supor que a organização dos currículos por competência - dialógica - deve ser expressão de uma construção democrática ${ }^{68}$, na qual a delimitação das competências e dos seus atributos seja oriundo de uma pactuação entre todos os envolvidos, incluindo representantes da instituição formadora - docentes, discentes e demais segmentos envolvidos - da sociedade civil organizada (p. ex., Conselho Municipal de Saúde), do sistema local de saúde (p. ex., Secretaria Municipal de Saúde), além de outras representações que por ventura sejam identificadas como legítimas. Vale ressaltar, neste contexto, que a competência dialógica não é redutível à concepção empresarial de competência - corporativa, individualista, modulante e vorazmente competitiva -, devendo ser compreendida enquanto síntese de possibilidades e potencialidades de diferentes atores implicados nas ações de atenção integral à saúde. Sendo assim, o processo de formação precisa considerar o encontro dos estudantes das diversas profissões da saúde com os usuários do SUS, especialmente no mundo do trabalho, para produção de um cuidado integral e integrado, que considere a complexidade da vida, do processo saúde-doença e da atenção aos sujeitos e às coletividades ${ }^{69}$.

\section{Para não concluir ...}

As questões complexas, por definição, não podem se render às respostas simplistas. Nestes termos, ao mesmo tempo em que a necessidade de transformar a educação profissional em saúde é uma constatação ${ }^{70}$ - na medida em que os confinamentos disciplinares não se sustentam (a passagem por espaços "fechados" dentro dos próprios cursos: anatomia, bioquímica, semiologia, cirurgia, dentre outros) -, corre-se o risco de se constituir modelos de formação que se inscrevam, acriticamente, nos moldes do capitalismo tardio e das sociedades de controle, de modo a manter funcionantes determinados dispositivos para o exercício de poder e de captura das subjetividades ${ }^{5}$.

Como compor tal situação? Como pensar a formação do profissional crítico, reflexivo e cida- 
dão, capaz de atuar em termos de resistência e de transformação social, como preconizado nas DCN dos cursos de graduação da área de saúde? Será este um 'beco sem saída', uma aporia? É preciso pensar. Estes momentos aporéticos são aqueles nos quais se faz mais necessário colocar o pensamento em ação, rejeitando o [que parece] óbvio e buscando novas orientações para o engajamento.

Com efeito, no que concerne ao conceito de competências no campo da educação e da saúde, é necessária a manutenção de uma perspectiva crítica, por sua relação intrínseca com as mudanças no padrão de acumulação capitalista e das novas formas de exploração do trabalho. No entanto, tal conceito - em sua proposta dialógica
- parece apontar para outra perspectiva, libertadora, na qual se pode reconfigurar a formação dos trabalhadores da área da saúde, no sentido de aproximar a formação profissional não apenas das necessidades biológicas - ou mais diretamente relacionadas ao que se costuma entender por saúde e por doença -, mas também em um terreno ético-político que permita contribuir com a construção de lógicas mais solidárias de existência nas relações entre as pessoas.

Esta é a aposta, talvez mais do que um o convite para pensar e agir: a criação de novas lógicas para a organização curricular dos espaços-tempos de educação dos profissionais da saúde, comprometidos, dialogicamente, com o cuidado.

\section{Colaboradores}

R Siqueira-Batista e AP Gomes conceberam a estrutura original e o argumento do presente artigo, tendo trabalhados juntos, especialmente, nas seções "Introdução" e "A crítica: a formação por competências no século XXI - capitalismo tardio e sociedade de controle". VS Albuquerque, FOL Cavalcanti e RMM Cotta contribuíram especialmente nas seções "Educação para o SUS" e "O (s) currículo(s) organizado(s) por competências e a formação em saúde: polissemia e opções teórico-práticas”. Todos os autores colaboraram com as seções "O currículo por competências na formação de profissionais para o SUS: resistência ao capitalismo tardio" e "Para não concluir" e revisaram a versão final do manuscrito.

\section{Agradecimentos}

Este artigo se vincula ao projeto de pesquisa Bioética na formação do profissional de saúde: construindo discursos e práxis no espaço-tempo da estratégia saúde da família, subsidiado pelo $\mathrm{CNPq}$ e pela FUNARBE. 


\section{Referências}

1. Prigogine I. O fim das certezas. São Paulo: Unesp; 1996.

2. Schramm FR. Bioética para quê? Revista Camiliana da Saúde 2002; 1(2):14-21.

3. Baudrillard J. A Sociedade de consumo. Lisboa: Ediç̃es $70 ; 1981$.

4. Deleuze G. Post-scriptum sobre as sociedades de controle. In: Deleuze G, organizador. Conversações: 1972-1990. Rio de Janeiro: Editora 34; 1992.

5. Siqueira-Batista R, Batista RS. Os anéis da serpente: a aprendizagem baseada em problemas e as sociedades de controle. Cien Saude Colet 2009; 14(4):11831192.

6. Feuerwerker L. Além do discurso de mudança na educação médica: processos e resultados. São Paulo, Londrina, Rio de Janeiro: Hucitec, Rede Unida, ABEM; 2002.

7. Ceccim RB, Feuerwerker LCM. Mudança na graduação das profissões de saúde sob o eixo da integralidade. Cad Saude Publica 2004; 20(5):1400-1410.

8. Venturelli J. Educación médica: nuevos enfoques, metas y métodos. 2a Edição. Washington, DC: OPAS/OMS; 2003.

9. Brasil. Ministério da Saúde (MS). Promed - Programa de Incentivo às Mudanças Curriculares para as Escolas Médicas. Brasília: MS; 2002.

10. Brasil. Ministério da Saúde (MS). Ministério da Educação. Pró-Saúde: Programa Nacional de Reorientação da Formação Profissional em Saúde. Brasília: MS; 2005.

11. Hernández D. Políticas de certificación de competencias en América Latina. In: Cinterfor. Competencia laboral y valorización del aprendizaje. Montevideo: Cinterfor, OIT; 2002. (Boletin Técnico Interamericano de Formación Profesional, n. 152)

12. Freire P. Pedagogia da Autonomia. São Paulo: Paz e Terra; 2003.

13. Coll C. Psicologia e currículo: uma aproximação psicopedagógica à elaboração do currículo escolar. São Paulo: Ática; 2000.

14. Foucault M. Microfísica do poder. $29^{a}$ Edição. Rio de Janeiro: Graal; 2010

15. Brasil. Constituição da República Federativa do Brasil. São Paulo: Ed. Revista dos Tribunais; 2000.

16. Brasil. Ministério da Saúde. Secretaria de Gestão do Trabalho e da Educação em Saúde. Curso de Especialização em Ativação de Processos de $\mathrm{Mu}$ dança na Formação Superior dos Profissionais da Saúde. Caderno do especializando. Rio de Janeiro: ENSP, Fiocruz; 2005.

17. Lima VV, Feuerwerker LCM. Formação de ativadores de processos de mudança - uma estratégia do AprenderSUS. Olho Mágico 2004; 11(4):15-18.

18. Pinheiro R, Ceccim RB. Experienciação, formação, cuidado e conhecimento em saúde: articulando concepções, percepções e sensações para efetivar o ensino da integralidade. In: Pinheiro R, Ceccim RB, Mattos RA, organizadores. Ensinar saúde: a integralidade e o SUS nos cursos de graduação na área da saúde. 2a Edição. Rio de Janeiro: Lappis; 2006.
19. Brasil. CNE. Diretrizes Curriculares Nacionais do Curso de Graduação em Medicina. Resolução CNE/ CES No. 4, Brasília, 7 de novembro, 1-6, 2001a.

20. Brasil. CNE. Diretrizes Curriculares Nacionais do Curso de Graduação em Enfermagem. Resolução CNE/ CES No. 3, Brasília, 7 de novembro, 1-6, 2001b.

21. Brasil. CNE. Diretrizes Curriculares Nacionais do Curso de Graduação em Odontologia. Resolução CNE/ CES No. 3, Brasília, 19 de fevereiro, 1-4, 2002.

22. Siqueira-Batista R, Helayel Neto JA. Einstein e a educação. Rev Bras Edu Méd 2008; 32(2):271-272.

23. Smolka MLRM. A construção da autonomia pedagógica do estudante e o ensino das ciências da saúde: pelas veredas da educação médica [dissertação]. Rio de Janeiro: IFRJ; 2011.

24. Almeida M, organizadores. Diretrizes Curriculares Nacionais para os Cursos Universitários na Área da Saúde. Londrina: Rede Unida; 2003.

25. Mehry EE. Em busca do tempo perdido: a micropolítica do trabalho vivo em saúde. In: Mehry EE, Onocko R, organizadores. Agir em saúde: um desafio para o público. São Paulo: Hucitec; 1997.

26. Siqueira-Batista R, Rôças G. Alfabetização ecológica. Rev Bras Edu Méd 2009; 33(1):123-125.

27. Pereira IB, Lima, JCF. Educação Profissional em Saúde. In: Dicionário da Educação Profissional. Rio de Janeiro: EPSJV; 2006. p. 126-132.

28. Hirata H. Da polarização das qualificações ao modelo da competência. In: Ferreti CJ, Zibas DML, Madeira FR, Franco MLPB, organizadores. Novas tecnologias, trabalho e educação: um debate multidisciplinar. Petrópolis: Vozes; 1994.

29. Frigotto G. Educação, crise do trabalho assalariado e do desenvolvimento: Teorias em conflito. In: Frigotto G, organizador. Educação e crise do trabaTho: perspectivas de final de século. $8^{\text {a }}$ Edição. Petrópolis: Vozes; 1998.

30. Perrenoud P. Construir as competências desde a escola. Porto Alegre: Artmed; 1999.

31. Valle R. O conhecimento em ação: novas competências para o trabalho no contexto da reestruturação produtiva. Rio de Janeiro: Relume Dumará; 2003.

32. Ramos MN. A educação profissional pela pedagogia das competências e a superfície dos documentos oficiais. Educ. Soc. 2002; 23(80):401-422.

33. Moreira COF. Entre o indivíduo e a sociedade: Um estudo da filosofia da educação de John Dewey. Bragança Paulista: EDUSF; 2002.

34. Dejours C. O fator humano. Rio de Janeiro: FGV; 1997.

35. Araújo AJS. A organização sob a ótica das eventos e da competência: a visão de Phillipe Zarifian. Revista Conceitos 2004; 10

36. Jobert G. A inteligência no trabalho. In: Carré P, Caspar P, organizadores. Tratado das ciências e das técnicas da formação. Lisboa: Instituto Piaget; 1999.

37. Frigotto G. Trabalho. In: EPSJV - Observatório dos Técnicos em Saúde, organizador. Dicionário da educação profissional em saúde. Rio de Janeiro: EPSJV; 2006. 
38. Barros FS, Pinheiro R. Notas teóricas sobre a noção de competência: discutindo cuidado e humanização na saúde. In: Pinheiro R, Barros MEB, Mattos RA, organizadores. Trabalho em equipe sob $o$ eixo da integralidade: valores e práticas. Rio de Janeiro: CEPESC, IMS, UERJ, ABRASCO; 2007. p. 111-128.

39. Heidegger M. Ensaios e conferências. $7^{\text {a }}$ Edição. Petrópolis: Vozes; 2010.

40. Silva CC, Egry EY. Constituição de competências para intervenção no processo saúde-doença da população: desafio ao educador de enfermagem. Esc Enferm USP 2003; 37(2):11-16

41. Desaulniers JBR. Formação, competência e cidadania. Educação \& Sociedade 1997; 18(60):51-63.

42. Costa TA. A noção de competência enquanto princípio de organização curricular. Rev Bras Edu 2005 29(2):52-63.

43. Ramos MN. A pedagogia das competências: autonomia ou adaptação? 3a Edição. São Paulo: Cortez; 2006.

44. Foucault M. A Vontade do Saber. Rio de Janeiro: Graal; 1977.

45. Kafka F. O processo. São Paulo: Companhia das Letras; 1997.

46. Chevitarese LP. A questão da "liberdade" na sociedade de controle, por uma alegoria de Kafka em O processo. Análogos 2004; 4:44-60.

47. Foucault M. Ditos e escritos $I V$ : estratégia, podersaber. Rio de Janeiro: Forense Universitária; 2003.

48. Negri A. Cinco lições sobre o império. Rio de Janeiro: DP\&A; 2003.

49. Dostoiévski F. Memórias da casa dos mortos. Porto Alegre: L\&PM; 2008.

50. Virilio P. O Espaço Crítico. Rio de Janeiro: Editora 34; 1993.

51. Niccol A. Gattaca - a experiência genética (filme). Hollywood: Columbia Pictures Corporation; 1997.

52. Alexandrowicz AMC. O paradigma da complexidade no século XXI: da filosofia e ética da biologia a uma evolução antropológica e psicoafetiva em curso [tese]. Rio de Janeiro: ENSP, Fiocruz; 2007.

53. Martins AM. A política do conhecimento: a identidade do saber e as reformas educativas. In: Linhares C, organizador. Políticas do conhecimento. Velhos contos, novas contas. Niterói: Intertexto; 1999. p. 71-100.

54. Caponi S. Biopolítica e medicalização dos anormais. Physis 2009; 19(2):529-549.

55. Ceccim RB, Merhy EE. Um agir micropolítico e pedagógico intenso: a humanização entre laços e perspectivas. Inteface - Comun Saúde Educ 2009; 13(Supl. 1):531-542.

56. Siqueira-Batista R. O cuidado integral em questão: diálogos entre filosofia e medicina (Editorial). Brasília Médica 2010; 47:273-275.

57. Araujo LF, Coelho CG, Mendonca ET, Vaz AVM, Siqueira-Batista R, Cotta RMM. Evidências da contribuição dos programas de assistência ao idoso na promoção do envelhecimento saudável no Brasil. Rev. panam. salud pública 2011; 30(1):80-86.
58. Freitas LMR, Siqueira-Batista R, Guedes AGM, Bevilaqua AATP, Andrade MKN. Tuberculose: recomendações para o diagnóstico, o tratamento e a prevenção. Rio de Janeiro: Assessoria de Pneumologia Sanitária da SESDEC; 2008.

59. Aristóteles. A Política. Coleção Os Pensadores. São Paulo: Nova Cultural; 2000.

60. Agamben G. Homo Sacer. O Poder soberano e a vida nua. Belo Horizonte: UFMG; 2004

61. Legião Urbana. Dois. São Paulo: Emi Odeon; 1986.

62. Albuquerque VS, Siqueira-Batista R, Tanji S, Moço ETSM. Currículos disciplinares na área de saúde: ensaio sobre saber e poder. Inteface - Comun Saúde Educ 2009; 13(31):261-272.

63. Lima VV. Competência: Distintas abordagens e implicações na formação dos profissionais da saúde. Inteface Comun Saúde Educ 2005, 9(17):369-379.

64. Brasil. Ministério da Saúde (MS). Secretaria de Gestão do Trabalho e da Educação na Saúde. Construção de processos educativos a partir de competências profissionais. In: $5^{a}$ Reunião Geral da Rede de Escolas Técnicas do SUS. Maceió: MS; 2006.

65. Gomes RS, Pinheiro R, Guizardi FL. A orquestração do trabalho em saúde: um debate sobre a fragmentação das equipes. In: Pinheiro R, Mattos RA, organizadores. Construção social da demanda. Rio de Janeiro: CEPESC, IMS, UERJ, ABRASCO; 2005.

66. Henriques RLM. Interlocução entre ensino e serviço: possibilidades de ressignificação do trabalho em equipe na perspectiva da construção social da demanda. In: Pinheiro R, Mattos RA, organizadores. Construção social da demanda. Rio de Janeiro: CEPESC, IMS, UERJ, ABRASCO; 2005.

67. Bourdieu P, Passeron JC. A reproducão: elementos de uma teoria do sistema de ensino. Petrópolis: Vozes; 2008.

68. Lima MG, Torrez MNFB, Gussi MA. A integralidade e a enfermagem na competência coletiva do cuidar em saúde. Tema Central do $59^{\circ}$ Congresso Brasileiro de Enfermagem. Brasília: ABEn-DF; 2007.

69. Albuquerque VS, Tanji S, Silva CMSLMD, Felippe K. Competência, competência coletiva e integralidade do cuidado enquanto princípios norteadores do novo currículo do curso de enfermagem do UNIFESO. In: Anais do 59 Congresso Brasileiro de Enfermagem 2007; Brasília, ABEn-DF; 2007.

70. Gomes AP, Rego S. Transformação da educação médica: é possível formar um novo médico a partir de mudanças no método de ensino-aprendizagem? Rev Bras Edu Méd 2011; 35(4):557-566.

Artigo apresentado em 01/10/2011

Aprovado em 25/03/2012

Versão final apresentada em 07/04/2012 